\title{
Hvem kan eie hellig grunn?
}

Et blikk på verdensbildet til de jødiske nybyggerne i Hebron.

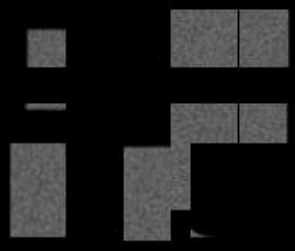

Hanne E. Røislien er forsker ved Institutt for fredsforskning (PRIO) i Oslo.

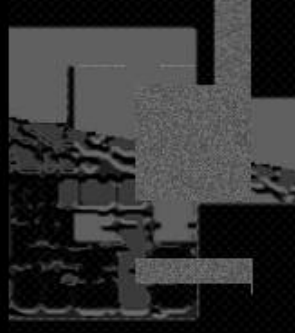

इes:
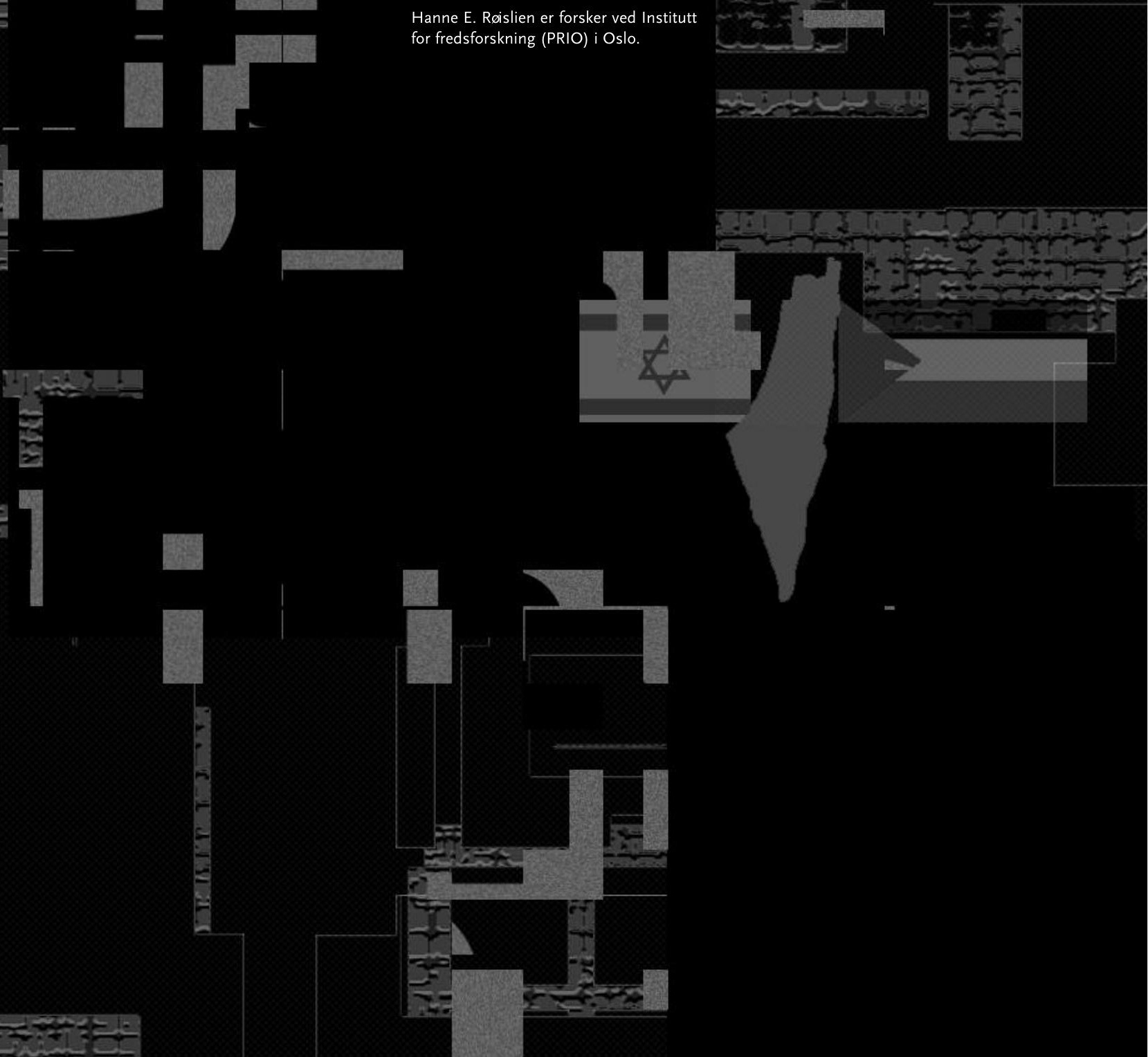
TEKST: Hanne E. Røislien

SOM DEN ENESTE BYEN av sitt slag på Vestbredden, finner man i Hebron et lite jødisk samfunn på kun 500 medlemmer midt blant en palestinsk befolkning som teller nærmere I30 ooo. Medlemmene av dette samfunnet representerer noen av de mest ytterliggående elementer innenfor den jødiske nybyggerbevegelsen. De motsetter seg kategorisk, både i ord og handling, ethvert forslag om å dele makt og autoritet over Hebron med palestinerne. Av israelske myndigheter anklages dette jødiske samfunnet for systematiske og voldelige angrep på palestinere, og for å sette palestinsk sikkerhet som sådan på spill.

Hva ligger til grunn for denne gruppens utbredte voldsutøvelse? Hvorfor er samhandling med den palestinske befolkningen utelukket? ${ }^{\text {r }}$
Hebron, som ligger cirka 35 kilometer sør for Jerusalem, omtales ofte som "Israel/Palestina-konflikten i et nøtteskall", ettersom palestinere og jøder her bor i og sloss om den samme hellige grunn. Likevel er Hebron ingen gjennomsnittsby på Vestbredden. Byen er den eneste av sitt slag der man finner et jødisk samfunn midt inne blant palestinsk bebyggelse. I denne hellige byen bor to befolkningsgrupper som er religiøst konservative, med verdensbilder som til dels kategorisk utelukker hverandre. Hebron oppnår sin hellige status fordi graven til patriarken Abraham de monoteistiske religioners "stamfar" befinner seg midt i Hebrons gamleby, hvilket gjør byen hellig for både jøder, kristne og muslimer. Innenfor jødisk religiøs forståelse er Abrahams grav også graven til hans hustru Sarah, samt Isak og Rebekka, Jakob og Lea. Med andre ord er det jødiske folkets mytologiske opphav gravlagt i Hebron, noe som har ført jødiske nybyggere med et radikalt nasjonalreligiøst verdensbilde til byen.

På tross av de religiøse aspektene som er knyttet til byen, er det langt fra en sakral stemning som møter Hebrons besøkende. Rusler man gjennom Hebrons gamleby må man ta turen forbi veisperringer, piggtrådgjerder, israelske kontrollposter bemannet med tungt bevæpnede soldater, rester av brennende bilhjul og palestinske hjem med gitter foran vinduene. Ettersom israelere, i motsetning til palestinere, har rett til å bevæpne seg, er det ikke uvanlig å se en jødisk kvinnelig nybygger i Hebron ha sitt barn på den ene armen, og et Uzi maskingevær på den andre. Mennene har også mindre typer håndvåpen stukket i baklomma. På vegger og dører til palestinske hus er det mengder av hebraisk 
grafitti. Man kan lese krigsrop og slagord som “Hevn!”, “Død over araberne!”, “[Det jødiske] blod skal hevnes!” og " Det jødiske folk skal herske!". En talsmann for det jødiske samfunnet kommenterte grafittien ved å si at han "ikke husket å ha sett for mange [sic!] 'Død over araberne' -slagord" på palestinsk eiendom, og bemerket at det for det meste var enkle davidsstjerner som

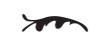

Hebron er jevnlig scene for sammenstøt. Kjernen $i$ denne kampen gjelder tilgangen til Abrahams grav.

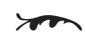

var sprayet på veggene. ${ }^{2}$ Dette er riktignok ikke den vanlige davidsstjernen: Disse davidsstjernene har en knyttneve inni, som er symbolet til et bannlyst, militant jødisk parti ved navn Kach. Kach har fortsatt sterkt fotfeste blant den jødiske befolkningen i Hebron.

Hebron er jevnlig scene for kraftige sammenstøt mellom palestinere og jødiske nybyggere. Kjernen i denne kampen gjelder tilgangen til Abrahams grav. ${ }^{3}$ Det mest alvorlige voldsutbruddet $\mathrm{i}$ byen $\mathrm{i}$ moderne tid hendte 25. februar I994. Da gikk den amerikansk-fødte nybyggeren doktor Baruch Goldstein inn i Abrahams grav midt i Hebron under fredagsbønnen og skjøt rundt seg, med det til følge at 29 palestinere ble drept. Goldstein ble selv slått til døde av fortvilte palestinere. Etter denne hendelsen, samt en rekke andre blodige sammenstøt $i$ byen, ble situasjonen så tilspisset $\mathrm{i}$ byen at israelske og palestinske myndigheter så seg nødt til å forsøke å dempe friksjonen mellom de ulike grupperingene i byen. Dermed forhandlet de fram Hebron Protocol for Redeployment, som siden 1997 har delt Hebron inn i to soner, henholdsvis $\mathrm{HI}$ og $\mathrm{H} 2 .{ }^{4}$ Gamlebyen $(\mathrm{H} 2)$ - og Abrahams grav - kom under israelsk sikkerhetskontroll, mens resten av byen, Hi, kom under palestinsk sikkerhetskontroll. Til dette uttalte det jødiske nybyggersamfunnet i Hebron følgende:

Oppgaven gitt til Abraham, den jødiske nasjons far, den forste til å bosette seg $i$ Hebron, har enda ikke blitt fullført. Vårt arbeid må fortsette på tross av all motgang. Det jødiske samfunnet $i$ Hebron fullbyrder denne oppgaven på vegne av hele Det jødiske folk. ${ }^{5}$

Det jødiske samfunnet i Hebron har med andre ord verken anerkjent eller respektert de forpliktelser som er nedtegnet i avtalen. Tvert imot; de kjemper med nebb og klør for sin tilstedeværelse, og motsetter seg samtidig palestinernes krav på byen.

\section{Barn av sin tid}

For å forstå verdensbildet til det jødiske samfunnet i Hebron, må man gå tilbake til Seksdagerskrigen i i967: I kjølvannet av denne krigen etablerte staten Israel den bosettingspolitikken som man ser resultater av i dag, på samme tid som den ytterliggående jødiske nybyggerbevegelsen tok form. Da Israel etter krigen satt igjen med enorme landområder, Vestbredden inkludert, kom spørsmålet om hva man skulle giøre med disse landområdene opp. Det israelske samfunnet delte seg raskt $i$ to fløyer. På den ene siden sto de som hevdet at man burde gi opp områdene først som sist. På motsatt floy sto det som ble betegnet som Greater Israel Movement; en folke- 
bevegelse som hevdet at områdene måtte forbli i israelske hender. Innenfor denne bevegelsen ble det hovedsakelig fremmet to argumenter: Fra et militær synspunkt, ble Vestbredden ansett som en "buffersone" mot den arabiske verden, og det ble antatt at et jødisk demografisk flertall var den mest effektive metoden for å sikre israelsk territoriell integritet $i$ et sterkt befolket arabisk område. Dermed ble det etablert bosettinger som ga jøder eksklusiv borett på Vestbredden. En annen fortolkning av situasjonen ble lagt fram av en gren av den religiøse, sionistiske fløyen, som forsto opprettelsen av staten Israel i I948 som et guddommelig tegn på at opprettelsen av Davids rike i den messianske tidsalder hadde begynt. De oppfattet enhver som bidro til å befolke Vestbredden som en religiøs aktør. Utvidelse av det jødiske territorium i I967 ble derfor oppfattet som et tegn på at den messianske tidsalder var kommet. $^{6}$

Selv om argumentene innenfor Greater Israel Movement var noe ulike, var konsekvensene det samme: Bosetting av de okkuperte områdene. Det har medført at Israel i dag kontrollerer over 60 prosent av Vestbredden og Gaza. I dag utgjør de sekulære og religiøse nybyggerne - konservative så vel som militante eller ultraortodokse - cirka 210.000 på Vestbredden, I80.000 i områdene rundt ØstJerusalem og 6000 i Gaza. I begge områdene er det i tillegg en massiv israelsk militær tilstedevæelse.

\section{I frelsens tidsalder er vold legitimt}

Fulle av pågangsmot og hellig overbeviste om at de nyerobrede områdene i Landet Israel måtte beboes, satte nybyggerne i gang med å etablere bosettinger. Hebron var den første byen som ble forsøkt bosatt av den religiøse sionistiske bevegelsen etter seksdagerskrigen, så tidlig som i I968. For å nå deres mål om å etablere og konsolidere jødiske bosettinger over hele Vestbredden, har de tatt alle midler i bruk - inkludert sivil ulydighet. Dette har ført til en rekke sammenstøt, ikke bare med palestinere, men også med israelske myndigheter. Det har vært en bitter dragkamp, men over tid har fire mindre bosettinger blitt etablert midt i Hebron og samfunnet har oppnådd anerkjennelse fra konservative israelske regjeringer, noe som har resultert $i$ at de nyter militær beskyttelse fra det israelske militæret døgnet rundt.?

Tilstedeværelsen baseres på en grunnleggende forståelse av Hebron som et hellig sted. Hebron gis avgiørende symbolsk betydning i den mytiske historien som ligger til grunn for nybyggernes religiøse verdensbilde, som i hovedsak er basert på et mytisk rammeverk med tre grunnantagelser.

For det første: Landet Israel har en iboende hellighet og Hebron er en hellig by med avgiørende betydning innenfor dette landet. For det andre: Det jødiske folk har et ansvar for andre nasjoners frelse. Og for det tredje: Vår tid er begynnelsen på frelsens tidsalder, og i denne tidsalder må det jødiske folk og landet Israel forenes. Med andre ord er det enhver jødes plikt å bosette seg i det hellige land. Det er altså en hellig plikt å etablere bosettinger for å framskynde den endelige frelsen for alle nasjoner. Det jødiske folk er dermed en aktiv deltager $\mathrm{i}$ etableringen av det messianske riket, og således også i frelsens framdrift. I denne messianske prosessen er den teokratiske lovgivningen den eneste gjeldende. 
Denne teologien må sees i klar sammenheng med sin politiske kontekst. Forklaringen på tilstandene i Hebron, og de standpunktene medlemmene av det jødiske samfunnet har inntatt, er relatert til den situasjonen som de selv mener å befinne seg i. Ytre politiske forhold medfører endringer $i$ verdensbildet og således også i handlingsmønstrene. Forholdet mellom verdensbilde og vold endrer seg når voldelige konflikter vedvarer. En konfliktfylt hverdag vil kunne endre den religiøse virkelighetsforståelsen. Når kulturelle aktører til stadighet beveger seg i en verden preget av konflikt og vold, blir nettopp dette en del av dagliglivet, av virkelighetsforståelsen; der vold og andre konfliktelementer er dagligdags, blir vold nærmest helt vanlig. Dette gjelder også for det jødiske samfunnet i Hebron.

De hellige tekster og den religiøse tradisjon som det jødiske samfunnet i Hebron henviser til for å begrunne sin tilstedeværelse i Hebron, strekker ikke til i forklaringen av deres voldelige handlinger, ei heller som begrunnelse for deres ytterliggående politiske tilknytning. Det er således et skille mellom den teologiske begrunnelsen for Hebrons hellighet, og de handlinger som det jødiske samfunnet i Hebron utfører i byrommet. For å finne begrunnelsen for dette, må man gå til den kulturelle og politiske kontekst som dette samfunnet befinner seg i, og de erfaringer de opplever å ha gjort seg.

Man skal ikke studere det jødiske samfunnet lenge før man får øye på en sterk mistillit mot ikke-jøder generelt, og den arabiske befolkningen spesielt. Det er heller ikke til å komme fra; den største "trusselen" mot det jødiske samfunnets forsøk på å gjøre Hebron til en jødisk by er selvsagt palestinerne. Blant nybyggerne er mistilliten til arabere blandet med behovet for å forsvare det hellige landskapet. Dermed kan man forklare hvordan en av mine informanter kunne hevde at tilsynela-

\section{mom \\ Man må tilbake til Seksdagers- krigen i 1967 for å forstå verdens- bildet til jødene i Hebron.}

tende ekstreme voldshandlinger bare er et uttrykk for landets "iboende hellighet", der jøder utfører sin plikt til å bebo landet og samtidig bekjemper ethvert hinder som står i veien for dette. Det hellige kravet overstyrer de sekulære lovene, og setter påbudet om å beskytte det hellige land foran ethvert verdslig lovverk.

Innenfor en slik forståelsesramme fremstår den palestinske motstanden som et av de største hindrene for utvidelsen av bosettingene, og forstås således som et element som må fjernes. Konflikten i Hebron har utviklet seg til å anta form av et nullsum-spill, der enhver utvidelse av den jødiske bosetningen skjer på bekostning av palestinsk eiendom, og teologiske nyfortolkninger av situasjonen gjennom disse nybyggernes øyne framholder at det $\mathrm{i}$ denne kampen kun er jødiske liv som må skånes i kampen for å bebo det hellige land. Nybyggerne forstår sine handlinger som integrert i en apokalyptisk visjon som leder til etableringen av det messianske riket. Følgelig er vold mot palestinere et legitimt middel. Den voldspregede samtiden som det jødiske samfunnet befinner seg i har således blitt nyfortolket som en nødvendighet for frelsesprosessen. Jo større 
friksjonen er, jo sterkere er de messianske krefter som frigis. Således er verdensbildet til det jødiske samfunnet i Hebron meget motstandsdyktig mot kritikk.

\section{Kampen fortsetter}

Det jødiske samfunnet i Hebron fortsetter sin kamp i en militarisert virkelighet preget av vold og konflikt. Den israelske sikkerhetstjenesten Shin Bet anser dette samfunnet for å være en sentral årsak til den gradvise forverringen av situasjonen på Vestbredden. ${ }^{8}$ I en upublisert rapport skrevet i 2002 om situasjonen i Hebron, var Shin Bet nådeløs overfor de jødiske nybyggerne. Vedrørende rapporten kunne man lese følgende i den israelske avisa Ha' aretz:

“Nok en gang ble det gjort klart for alle hvordan ekstremistene blant nybyggerne bidrar til å forsterke spiralen av hat og vold. Volden i Hebron er bevis på hvor umulig det er å opprettholde noen form for sameksistens mellom nybyggere og palestinere $i$ de okkuperte områdene, og hvilken enorm betydning ekstremistene har for forverringen av konflikten." 9 (Ha' aretz 30/07/02, min oversettelse).

På tross av tung kritikk, både fra nasjonale og internasjonale organer, holder det jødiske samfunnet i Hebron stand, slik de har gjort kontinuerlig siden Israel fikk kontrollen over Hebron igjen etter Seksdagerskrigen i I967. Siden den gang har samfunnet utviklet seg til å integrere vold og konflikt som ledd i en større teologi om Hebron. Skal man forsøke å forstå denne utviklingen ikke bare på et intellektuelt, men også et emosjonelt plan, kan man stille seg spørsmålet om hvordan man selv ville reagert dersom det man tror på trues av andre? Hvis hele ens eksistensgrunnlag står på spill, hvilke midler blir da legitime å ta i bruk? Ser man det jødiske samfunnet i Hebron i en slik historisk og politisk sammenheng, kan man lettere forstå dagens situasjon. Dette betyr ikke å legitimere voldshandlinger, men enhver konfliktløsning må begynne med en vilje til å forstå.

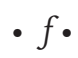

I Artikkelen baserer seg blant annet på en rekke intervjuer jeg gjorde i Hebron med medlemmer av bosetter-samfunnet i 2000 og 2002. Se Hanne Eggen Røislien, 200I, "Obligations of Sacred Place? An analysis of the Jewish Community of Hebron", hovedfagsoppgave i religionshistorie, Institutt for kulturstudier, Universitetet i Oslo.

2 Radin, Charles A., 200I, "Hebron's Jewish extremists $\mathrm{p}$ tected despite actions", Boston Globe, 23. november.

3 Se blant annet Ha' aretz 2002, "The Rulers of Hebron", editorial, I3. august.

4 Shlaim, Avi, 200I, «The Iron Wall. Israel and the Arab World». W.W. Norton \& Company, New York \& London.

5 Arnon, Noam (ed.) «Hebron. Past, Present and Forever». The Jewish Community of Hebron / The Hebron Fund, Beit El [Vestbredden] mai I999.

6 For behandlinger av dette temaet. Se Gideon Aran, I987, "From Religious Zionism to Zionist Religion. The Origins and Culture of Gush Emonim, a messianic movement in modern Israel": Thesis submitted for the Degree Doctor of Philosophy to the Senate of the Hebrew University of Jerusalem (avhandlingen er på hebraisk) og Ehud Sprinzak, I99I, «The Ascendance of Israel's Radical Right», Oxford University Press, New York.

7 Uoffisielle tall viser at bare i Hebron er det cirka I5002000 israelske soldater. Tallet avhenger av voldsnivået på konflikten.

8 Se blant annet Margot Dudkevitch, I998, "Israeli police open I43 criminal files on Hebron Jews", The Jerusalem Post, II. september og Jonathan Lis, 2002, "Court releases one of six suspects in Jewish bomb plot”, Ha' aretz, I6 mai.

9 Ha' aretz, 2002, "Fear and Violence in Hebron", 30. juli. Min oversettelse. 